\title{
冀东泥质变质岩中白云母 $b_{0}$ 值的初步研究
}

\author{
陈 翼飞 \\ （河北省地质局综合研究队） \\ 一、前言
}

萨西 ${ }^{[1,2]}$ 等对泥质变质岩中的钾质白色云母作了大量的 X 射线衍射分析,发现白云母 $b_{0}$ 值 随变质压力的增加而增大, 指出白云母 $b_{0}$ 值可以作为地质压力计, 他们建议按岩石中白云母 $b_{0}$ 值将变质作用划分三种压力类型，即高压型、中压型和低压型. 低压和中压的界限放在 $9.00 \AA$, 中压和高压的界限放在 $9.040 \AA$ (表 1 ).

叶大年等 ${ }^{[3]} 、$ 张旗 ${ }^{[1]}$ 等以及解广轰也作过类似的研究, 并得到相似的结论. 然而以前的研 究主要集中在新生代, 中生代造山带变质岩中白云母, 而对前寒武纪的变质岩的白云母的 $b_{0}$ 值注意较少. 在本文中, 作者将就冀东青龙县前寒武纪泥质变质岩中白云母 $b_{0}$ 值的初步研究 作简要的讨论.

\section{二、研究区域的地质概况}

在研究区域内太古界的单塔子群和元古界的朱拉子群广泛出露. 从青龙县的烧锅岔到杨 杖子 $\left(\mathrm{P}_{\mathrm{I}-\mathrm{I}}\right)$ 、从青龙县的蛇盘兔到杉树岭 $\left(\mathrm{P}_{\mathrm{II}-\mathrm{II}}\right)$ 作了两个地质剖面. 剖面 $\mathrm{P}_{\mathrm{I}-\mathrm{I}}$ 的前半部 仅包括朱杖子群的老李洞组和上白城子组, 而后半部份仅包括单塔子群的南店子组. 剖面 $\mathrm{P}_{\mathrm{II}-\mathrm{II}}$ 由朱杖子群的勃罗台组、上白城子组、老爷庙组. 两个剖面相隔大约 30 公里. 两个剖面 上产出的主要岩石类型是变粒岩、白云母片岩,角闪片岩、斜长角闪岩和变质火山岩.

为了诙复变质岩的原岩, 在我们的研究中采用了 Семененко ${ }^{[5]}$ 的 A-C-FM 图, $(\mathrm{al}+\mathrm{fm})-$ $(\mathrm{c}+\mathrm{alk})$ 对 $\mathrm{Si}$ 图解, 以及 $\mathrm{Shaw}^{[6]}$ 的判别式 $\mathrm{DF}=10.44-0.21 \mathrm{SiO}_{2}-0.32 \mathrm{Fe}_{2} \mathrm{O}_{3}$ (全铁)$0.98 \mathrm{MgO}+0.55 \mathrm{CaO}+1.46 \mathrm{Na}_{2} \mathrm{O}+0.54 \mathrm{~K}_{2} \mathrm{O}$, 对 $\mathrm{SiO}_{2}$ 含量大于 $53.5 \%$ 的岩石进行判别. 结 果说明, 原岩主要是粘土岩, 砂泥岩, 砂岩, 夹有基性、中酸性火山岩和火山碎屑岩.

剖面 $\mathrm{P}_{\mathrm{I}-\mathrm{I}}$ 中, 从朱杖子群采样 21 个, 从单塔子群南店子组中取样 7 个, 在剖面 $\mathrm{P}_{\mathrm{II}-\mathrm{II}}$ 中从 朱杖子群取样 20 个.

\section{三、白云母 $b_{0}$ 值的测定}

从每块样品中垂直片理锯下一块 $3 \times 15 \times 20 \mathrm{~mm}^{3}$ 的岩片, 安装在 Mikrometa II 型衍射 仪上. 用铜 $\mathrm{K}_{\alpha}$ 射线; 瀪滤波片; 扫描角度范围 $59-63^{\circ}$; 扫描速度 $2 \theta=1^{\circ} /$ 分; 记录纸速 $20 \mathrm{~mm} /$ 分. 岩片中的石英作为测量白云母 060 峰的内标. $b_{0}=6 \times d_{060}, b_{0}$ 值的平均误差 $\pm 0.003 \AA$ (表 2).

本文 1979 年 11 月 3 日收到.

第 1 期

科学通报

43 
表 1 不同压力类型变质带中白云母的 $b_{n}$ 值

\begin{tabular}{|c|c|c|c|c|c|}
\hline 变 质 带 & 样品数量 & $b_{0}$ 平均值 $(\AA)$ & 标准误差 (合) & 压力类型 & 备 \\
\hline 波索斯特 & 182 & 8.994 & 0.009 & 低压 & \multirow{7}{*}{ 根据萨西资料 } \\
\hline 领 家 & 46 & 9.013 & 0.006 & 低-中匡 & \\
\hline 北新罕布什尔 & 17 & 9.039 & 0.005 & 中匡 & \\
\hline 奥塔戈 & 35 & 9.039 & 0.005 & 中匡 & \\
\hline 东阿尔卑斯 & 100 & 9.038 & 0.008 & 中压 & \\
\hline 三波川 & 34 & 9.054 & 0.006 & 高匡 & \\
\hline 达代-巴利达格 & 46 & 9.056 & 0.007 & - 高压 & \\
\hline 喜马拉雅(聂拉木) & 16 & 9.031 & & 中匡 & \multirow{8}{*}{$\begin{array}{l}\text { * } \\
\text { 本文作者 } \\
\text { 本文作者 }\end{array}$} \\
\hline 藏南低分水岭 & 23 & 8.987 & & 低匡 & \\
\hline 雅急藏布(大拐弯) & 31 & 9.043 & & 中一高压 & \\
\hline 刚底斯 & 24 & 9.009 & & 低一中压 & \\
\hline 金沙江 & 21 & 9.012 & & 低一中匡 & \\
\hline 桉山群 & 40 & 9.030 & & 中 & \\
\hline 䝨东单塔子南店子组 & 7 & 8.994 & 0.012 & 低压 & \\
\hline 䝨东朱杖子群 & 41 & 9.008 & 0.012 & 低一中压 & \\
\hline
\end{tabular}

*解广轰,未刊资料。

表 2 冀东变质岩白云母的 $b_{0}$ 值

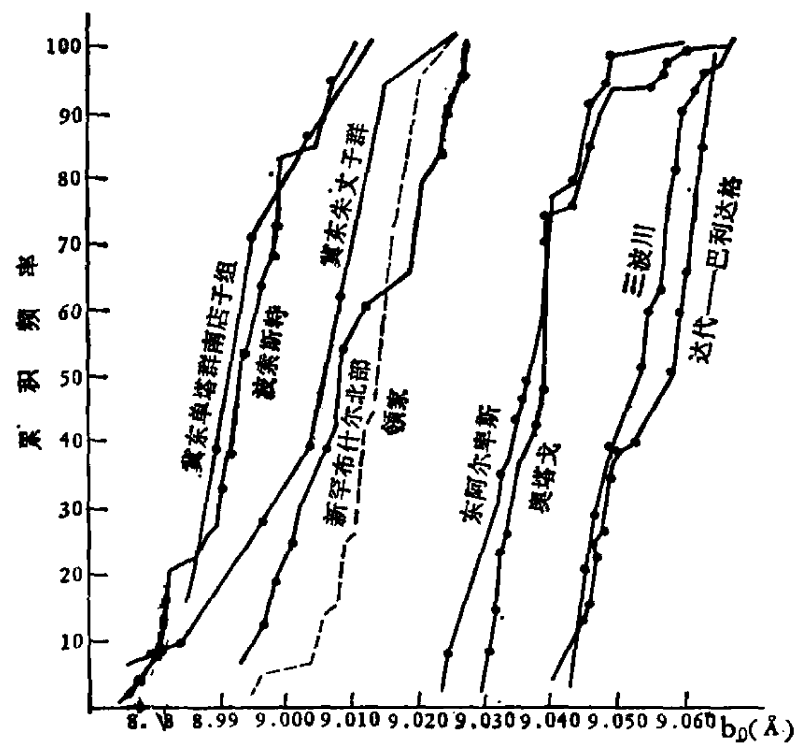

\begin{tabular}{|c|c|c|}
\hline & 剖面 $P_{I-1} b_{0} \AA$ & 剖面 $\mathrm{P}_{\mathrm{II}-\mathrm{nI}} b_{0} \AA$ \\
\hline \multirow[t]{2}{*}{ 群 } & $\begin{array}{l}9.012 \\
9.012 \\
9.018 \\
8.992 \\
9.018 \\
9.012 \\
9.016 \\
8.991 \\
9.030 \\
9.018 \\
9.005 \\
8.982 \\
9.018 \\
9.025 \\
9.005 \\
9.012 \\
8.997 \\
9.012 \\
9.018 \\
9.025 \\
9.018\end{array}$ & $\begin{array}{l}9.018 \\
9.018 \\
9.018 \\
9.016 \\
9.012 \\
8.976 \\
8.997 \\
9.004 \\
9.012 \\
8.997 \\
8.976 \\
9.012 \\
8.997 \\
9.018 \\
9.005 \\
9.012 \\
9.012 \\
8.990 \\
9.004 \\
9.005\end{array}$ \\
\hline & $b_{0}=9.005 \pm 0.013 \AA$ & $b_{0}=9.011 \pm 0.012 \AA$ \\
\hline 塔 & $\begin{array}{l}9.005 \\
8.988 \\
8.991 \\
9.018 \\
8.997 \\
8.991 \\
8.990\end{array}$ & \\
\hline 群 & $b_{0}=8.994 \pm 0.012 \AA$ & \\
\hline
\end{tabular}




\section{四、讨论}

1. 从图 1 可看出朱杖子群和单塔子群的累计频率曲线是明显分开的，属两种不同的压力 类型的区域变质作用, 这个结论与这两个群之间是角度不整合关系, 是相符的. 南店子组的累 计频率曲线和波索斯特群的曲线一致. 这两个群(组)的白云母 $b_{0}$ 的平均值是 $8.994 \AA$, 因而, 它们应属低压型的. 剖面 $P_{\mathrm{I}-\mathrm{I}}$ 和 $\mathrm{P}_{\mathrm{II}-\mathrm{II}}$ 朱杖子群的 $b_{0}$ 值比较稳定, 分别是 $9.005 \AA$ 和 $9.010 \AA$. 朱杖子群是一套低级变质岩, 没有遭受混合岩化, 以存在一个绿泥石一黑云母-铁铝榴石序列为 特征. 在图 1 中, 朱杖子群的曲线中值 $b_{0}=9.008 \AA$ 与新罕布什尔的中值 $b_{0}=9.000 \AA$ 接近, 亦与西藏冈底斯变质带一致 $\left(b_{0}=9.009 \AA\right)$, 因此, 朱故子群属于低压和中压之间的过渡类 型.

2. 测量的样品衍射图上没有双峰, 按张旗等人的意见, $\mathrm{X}$ 射线衍射图上 060 峰的数目代表 变质事件的次数, 喜马拉雅变质带经受过两次变质作用, 因为这个变质带泥质变质岩中白云母 衍射图上显出两个 $b_{0}$ 值 $(9.031 \AA$ 和 $8.993 \AA)$. 由于单塔子和朱杖子群的衍射图上是单峰, 意味着它们两者仅遭受一期变质作用.

3. 虽然,大多数前寒武纪变质作用属于巴罗型,上述两个地区是例外,这个事实表明,在前 寒武纪地壳并非各处地热梯度一致.

4. 以前国外白云母 $b_{0}$ 值的研究多集中在中新生代造山带的泥质变质岩中, 对前寒武纪的 白云母 $b_{0}$ 值研究较少, 中国几个地区的研究说明, 前寒武纪变质岩白云母 $b_{0}$ 值应该引起注意.

致谢: 中国科学院地质研究所 $\mathrm{x}$ 射线实验室在白云母 $b_{0}$ 值测定工作中提供了方便. 本工作是以本队黛 东铁矿研究组的野外研究工作为基础. 本队岩矿鉴定组、重砂矿物组的同志给予大力支持, 作者在此一并致 谢.

\section{参文献}

† 1 ] Sassi, F. P. \& Seolari, A., Contr. Min. Petrol., 45(1974), 143-152.

[ 2 ] Sassi, F. P., Krautner, H. G. \& Zirpoli, G.. Sohweiz. Min. Petrogr. Mitt., 56(1976), 427-434.

[3] 叶大年、李达周、董光复、邱秀文, 科学通报, 24(1979), 5:217一220.

[4] 张旗、张振禹、周云生、李炤华, 科学通报, 24(1979),3:120-123.

[5] Семененко Н. П., Метаморфизм подвижмых зон, Наукова Думка, Қиев, 1966.

[ 6 ] Shaw, D. M., Canada Jour. Earth. Soi., 9(1972), 18-35. 